\title{
When, where and how does microbial community composition matter?
}

\author{
Diana R. Nemergut ${ }^{1,2,3}{ }^{*}$, Ashley Shade ${ }^{4}$ and Cyrille Violle ${ }^{5}$ \\ ${ }^{1}$ Institute of Arctic and Alpine Research, University of Colorado, Boulder, CO, USA \\ 2 Environmental Studies Program, University of Colorado, Boulder, CO, USA \\ ${ }^{3}$ Department of Biology, Duke University, Durham, NC, USA \\ ${ }^{4}$ Department of Microbiology and Molecular Genetics, Michigan State University, East Lansing, MI, USA \\ ${ }^{5}$ CEFE UMR 5175, CNRS - Université de Montpellier - Université Paul-Valéry Montpellier - EPHE, Montpellier, France \\ *Correspondence: nemergut@colorado.edu
}

Edited by:

Lisa Y. Stein, University of Alberta, Canada

Reviewed by:

Ming Nie, University of Aberdeen, UK

Keywords: structure-function, biodiversity-ecosystem function, trait-based approaches, species-species interactions, ecological trade-offs, microbial community assembly, trait distributions

Our planet is experiencing rates of environmental change unprecedented in modern times, and an understanding of how microbes both mediate and respond to these shifts is an important research challenge (De Vries and Shade, 2013). Because of the temporal and spatial scales over which microbes function as well as their extreme diversity, dynamics in microbial structure and processes are typically examined at the community level. However, the factors that drive patterns in microbial structure and function, and the links between them, remain widely debated (Prosser et al., 2007). In this issue, such patterns in microbial communities are further documented for soils, lakes, streams and ocean provinces (Arnosti et al., 2012; Jones et al., 2012; King et al., 2012; Larouche et al., 2012). Additionally, the importance of spatial and temporal dynamics (Armitage et al., 2012; Arnosti et al., 2012; Jones et al., 2012; Larouche et al., 2012) and interactions with macrobiota (King et al., 2012) in driving these patterns is demonstrated. Yet, a central but unanswered question is: "does knowing who is there help us to better understand what they are doing?" Indeed, as shown here by Salles et al. (2012), links between structure and function can often be weak, both at the level of the individual and at the level of the community. Several papers in this special issue, "The Causes and Consequences of Microbial Community Structure," use empirical or modeling approaches as well as literature reviews to enrich our mechanistic understanding of the controls over the relationship between community structure and ecosystem processes. Specifically, authors address the role of trait distributions and trade-offs, species-species interactions, evolutionary dynamics, community assembly processes and physical controls in affecting "who's there" and "what they are doing."

Trait-based approaches can provide mechanistic links between community structure and function, and are gaining popularity in microbial ecology (Krause et al., 2014). Importantly, the distribution of traits within a community may affect the relationship between structure and function (Webb et al., 2010). Thus, as highlighted in this issue by Comte et al. (2013), traits can be considered at both the individual and the community level, where trait distributions may have important implications for emergent properties (e.g., redundancy). Indeed, Shade et al. (2012) highlight a variety of traits that may govern the stability of individual organisms, populations and communities including plasticity, tolerance and dormancy. Folse and Allison (2012) used a multinutrient, multi-genotype model of enzyme activity, and showed that trait distributions could yield insight into the relationships between biodiversity and ecosystem function. They found that generalists dominated at low levels of community diversity when rates of enzyme production and enzyme diffusion were lowest. Matias et al. (2013) used a simple microcosm experiment and examined the response of assembled communities to fluctuations in salinity. Their results were somewhat different from Folse and Allison (2012), as they found that community diversity was positively related to productivity and that generalists were more productive and less variable over time. Their work also showed that there did not appear to be a fitness trade-off associated with generalization. Comte et al. (2013) took a novel approach to examine plasticity and redundancy in freshwater bacterioplankton communities, and described explicit metrics to track these traits within community transplant experiments. They showed that plasticity appeared to be an intrinsic community property while redundancy was affected by external environmental factors. Their work also revealed strong relationships between community plasticity and redundancy, with no evidence for trade-offs and a possible co-selection of these attributes.

As well, species-species interactions can affect the relationship between communities and processes. In the model presented by Folse and Allison (2012), the importance of both "coalitions" of complementary organisms and the abundance of "cheaters," or organisms that use a public good without contributing to its production, increased under high levels of enzyme production. They also found that the presence of cheaters could affect the relationship between biodiversity and function. Fox (2012) offered a cautionary tale in terms of our ability to interpret relationships 
between abundance and "adaptedness" because of organismal interactions. He used a consumer-resource model to demonstrate that, at medium levels of niche overlap, outcomes of competition can be unpredictable, decoupling relationships between abundance and adaptation.

Evolutionary dynamics can also alter relationships between structure and function. In a Perspectives Article, Choudoir et al. (2012) advocate for population-level approaches to examining microbial community diversity, emphasizing that organisms with exactly the same $16 \mathrm{~S}$ rRNA gene sequence can exhibit very different ecological dynamics. Indeed, Salles et al. (2012) examined the links between rates of denitrification and phylogenies and highlighted the potential importance of horizontal gene transfer (HGT) by showing that similarity in nirK genes, which are thought to be subject to HGT, is not related to $\mathrm{N}_{2} \mathrm{O}$ accumulation rates. Furthermore, for nirS and 16S rRNA genes, Salles et al. (2012) showed that there was more explanatory power between structure and function at finer scales of phylogenetic resolution for denitrification and metabolic profiles respectively. Pearce et al. (2012) used metagenomics to examine a soil microbial community from Mars Oasis, Antarctica, and showed that while genera-level diversity was limited, species-level diversity was high. They proposed that this suggests strong selection on the types of taxa that can inhabit this extreme environment combined with high rates of diversification within those lineages. Related, Knope et al. (2012) used a microcosm approach to examine the importance of evolutionary history for diversification in bacteria. They showed that prior exposure to an environmental challenge led to higher rates of diversification. These studies suggest that understanding the coupling of ecological and evolutionary processes is key for interpreting microbial community patterns of structure and function.

Community assembly processes may also alter the relationship between "who's there" and "what they do" (Nemergut et al., 2013). Knope et al. (2012) found that arriving in a community first led to a greater degree of diversification within bacteria, likely because of niche-preemption. Pholchan et al. (2013) used a variety of manipulations to alter microbial community assembly in sludge reactors and showed that relationships between biodiversity and ecosystem function in these systems were unpredictable. They hypothesized that the relative importance of stochastic vs. deterministic assembly processes could change the relationship between biodiversity and ecosystem function. In their comment on the Pholchan manuscript, Knelman and Nemergut (2014) provide a conceptual framework illustrating how assembly, biodiversity and function may be related. Together, these studies provide growing evidence for the importance of assembly processes in determining microbial community properties.

Physical dynamics may also be key in regulating the relationship between structure and function. Schimel and Schaeffer (2012) propose a conceptual framework that highlights a requirement that biological processes need to be rate limiting or fate determining in order for community structure to matter for ecosystem function. For example, they propose that structure is not likely to be relevant for organic matter breakdown in mineral soils, where diffusion is limited and organic particles may be occluded or sorbed to soil surfaces. Likewise, Folse and Allison
(2012) demonstrate that rates of diffusion of enzymes can affect community diversity and the relative proportion of generalists to specialists. Their work also showed high rates of diffusion coupled to high rates of production can lead to community bottlenecks and increases in stochasticity. As well, King et al. (2012) found that physical dynamics may also affect biotic relationships. They found that associations between plants and microbial community composition were less pronounced at higher elevations, likely due to an increase in the influence of physical harshness on community composition.

Together, the studies in this special issue highlight the role of a variety of ecological, evolutionary and physical dynamics in microbial community structure and function (Figure 1). This body of work emphasizes the importance of emergent, aggregate community properties and the role of community dynamics in variations in the strength of the structure-function relationships. As Schimel wrote in 1995 "At a small enough scale, microbial community structure must be a dominant control on ecological processes, but as we move up in scale toward the ecosystem and integrate across many individual communities, the influence of microbial community structures decreases." Predicting when, where, how, and at what scale microbial communities may

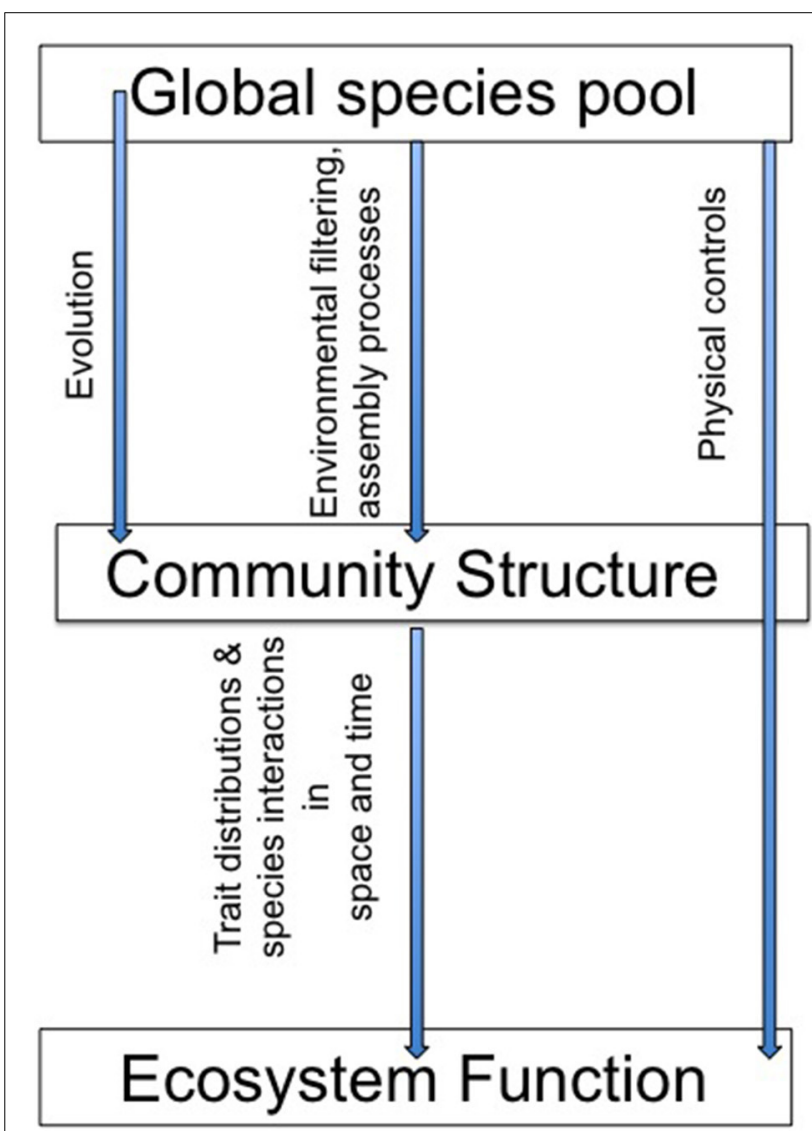

FIGURE 1 | Does "who's there" matter for "what they do"? The papers in this special issue use modeling, empirical approaches, and literature reviews to address a suite of controls over the relationship between community structure and ecosystem function. 
respond to environmental changes remains a research priority and these papers present new insights into this challenge.

\section{ACKNOWLEDGMENTS}

Cyrille Violle was supported by a Marie Curie International Outgoing Fellowship within the 7th European Community Framework Program (DiversiTraits project, no. 221060).

\section{REFERENCES}

Armitage, D. W., Gallagher, K. L., Youngblut, N. D., Buckley, D. H., and Zinder, S. H. (2012). Milimeter-scale patterns of phylogenetic and trait diversity in a salt marsh microbial mat. Front. Microbiol. 3:293. doi: 10.3389/fmicb.2012.00293

Arnosti, C., Fuchs, B. M., Amann, R., and Passow, U. (2012). Contrasting extracellular enzyme activities of particle-associated bacteria from distinct provinces of the North Atlantic Ocean. Front. Microbiol. 3:425. doi: 10.3389/fmicb.2012.00425

Choudoir, M. J., Campbell, A. N., and Buckley, D. H. (2012). Grappling with Proteus: population-level approaches to understanding microbial diversity. Front. Microbiol. 3:336. doi: 10.3389/fmicb.2012.00336

Comte, J., Fauteux, L., and Del Giorgio, P. A. (2013). Links between metabolic plasticity and functional redundancy in freshwater bacterioplankton communities. Front. Microbiol. 4:112. doi: 10.3389/fmicb.2013.00112

De Vries, F. T., and Shade, A. (2013). Controls on soil microbial community stability under climate change. Front. Microbiol. 4:265. doi: 10.3389/fmicb.2013. 00265

Folse, H. J. 3rd., and Allison, S. D. (2012). Cooperation, competition, and coalitions in enzyme-producing microbes: social evolution and nutrient depolymerization rates. Front. Microbiol. 3:338. doi: 10.3389/fmicb.2012.00338

Fox, J. W. (2012). When should we expect microbial phenotypic traits to predict microbial abundances? Front. Microbiol. 3:268. doi: 10.3389/fmicb.2012.00268

Jones, S. E., Cadkin, T. A., Newton, R. J., and McMahon, K. D. (2012). Spatial and temporal scales of aquatic bacterial beta diversity. Front. Microbiol. 3:318. doi: $10.3389 /$ fmicb. 2012.00318

King, A. J., Farrer, E. C., Suding, K. N., and Schmidt, S. K. (2012). Co-occurrence patterns of plants and soil bacteria in the high-alpine subnival zone track environmental harshness. Front. Microbiol. 3:347. doi: 10.3389/fmicb.2012.00347

Knelman, J. E., and Nemergut, D. R. (2014). Changes in community assembly may shift the relationship between biodiversity and ecosystem function. Front. Microbiol. 5:424. doi: 10.3389/fmicb.2014.00424

Knope, M. L., Forde, S. E., and Fukami, T. (2012). Evolutionary history, immigration history, and the extent of diversification in community assembly. Front Microbiol. 3:273. doi: 10.3389/fmicb.2011.00273

Krause, S., Le Roux, X., Niklaus, P. A., Van Bodegom, P. M., Lennon, J. T., Bertilsson, S., et al. (2014). Trait-based approaches for understanding microbial biodiversity and ecosystem functioning. Front. Microbiol. 5:251. doi: 10.3389/fmicb.2014.00251

Larouche, J. R., Bowden, W. B., Giordano, R., Flinn, M. B., and Crump, B. C. (2012). Microbial biogeography of arctic streams: exploring influences of lithology and habitat. Front. Microbiol. 3:309. doi: 10.3389/fmicb.2012.00309
Matias, M. G., Combe, M., Barbera, C., and Mouquet, N. (2013). Ecological strategies shape the insurance potential of biodiversity. Front. Microbiol. 3:432. doi: 10.3389/fmicb.2012.00432

Nemergut, D. R., Schmidt, S. K., Fukami, T., O’neill, S. P., Bilinski, T. M., Stanish, L. F., et al. (2013). Patterns and processes of microbial community assembly. Microbiol. Mol. Biol. Rev. 77, 342-356. doi: 10.1128/mmbr.00051-12

Pearce, D. A., Newsham, K. K., Thorne, M. A., Calvo-Bado, L., Krsek, M., Wellington, E. M., et al. (2012). Metagenomic analysis of a southern maritime Antarctic. Front. Microbiol. 3:403. doi: 10.3389/fmicb.2012.00403

Pholchan, M. K., Baptista, J. D. C., Davenport, R. J., Sloan, W. T., and Curtis, T. P. (2013). Microbial community assembly, theory and rare functions. Front. Microbiol. 4:68. doi: 10.3389/fmicb.2013.00068

Prosser, J. I., Bohannan, B. J. M., Curtis, T. P., Ellis, R. J., Firestone, M. K., Freckleton, R. P., et al. (2007). Essay - the role of ecological theory in microbial ecology. Nat. Rev. Microbiol. 5, 384-392. doi: 10.1038/nrmicro1643

Salles, J. F., Le Roux, X., and Poly, F. (2012). Relating phylogenetic and functional diversity among denitrifiers and quantifying their capacity to predict community functioning. Front. Microbiol. 3:209. doi: 10.3389/fmicb.2012. 00209

Schimel, J. (1995). "Ecosystem consequences of microbial diversity and community structure," in Arctic and Alpine Biodiversity: Patterns, Causes, and Ecosystem Consequences, eds F. S. Chapin and C. Korner (Berlin: SpringerVerlag), 239-254.

Schimel, J. P., and Schaeffer, S. M. (2012). Microbial control over carbon cycling in soil. Front. Microbiol. 3:348. doi: 10.3389/fmicb.2012.00348

Shade, A., Peter, H., Allison, S. D., Baho, D. L., Berga, M., Buergmann, H., et al. (2012). Fundamentals of microbial community resistance and resilience. Front. Microbiol. 3:417. doi: 10.3389/fmicb.2012.00417

Webb, C. T., Hoeting, J. A., Ames, G. M., Pyne, M. I., and Poff, N. L. (2010). A structured and dynamic framework to advance traits-based theory and prediction in ecology. Ecol. Lett. 13, 267-283. doi: 10.1111/j.1461-0248.2010. 01444.x

Conflict of Interest Statement: The authors declare that the research was conducted in the absence of any commercial or financial relationships that could be construed as a potential conflict of interest.

Received: 06 August 2014; accepted: 03 September 2014; published online: 26 September 2014.

Citation: Nemergut DR, Shade A and Violle C (2014) When, where and how does microbial community composition matter? Front. Microbiol. 5:497. doi: 10.3389/ fmicb.2014.00497

This article was submitted to Terrestrial Microbiology, a section of the journal Frontiers in Microbiology.

Copyright (c) 2014 Nemergut, Shade and Violle. This is an open-access article distributed under the terms of the Creative Commons Attribution License (CC BY). The use, distribution or reproduction in other forums is permitted, provided the original author(s) or licensor are credited and that the original publication in this journal is cited, in accordance with accepted academic practice. No use, distribution or reproduction is permitted which does not comply with these terms. 